\title{
Comparison of methodological quality rating of systematic reviews on neuropathic pain using AMSTAR and R-AMSTAR
}

Svjetlana Dosenovic ${ }^{1,2}$, Antonia Jelicic Kadic ${ }^{2,3}$, Katarina Vucic ${ }^{4}$, Nikolina Markovina ${ }^{2}$, Dawid Pieper ${ }^{5}$ and Livia Puljak $k^{2,6^{*}}$

\begin{abstract}
Background: Systematic reviews (SRs) in the field of neuropathic pain (NeuP) are increasingly important for decision-making. However, methodological flaws in SRs can reduce the validity of conclusions. Hence, it is important to assess the methodological quality of NeuP SRs critically. Additionally, it remains unclear which assessment tool should be used. We studied the methodological quality of SRs published in the field of NeuP and compared two assessment tools.

Methods: We systematically searched 5 electronic databases to identify SRs of randomized controlled trials of interventions for NeuP available up to March 2015. Two independent reviewers assessed the methodological quality of the studies using the Assessment of Multiple Systematic Reviews (AMSTAR) and the revised AMSTAR (R-AMSTAR) tools. The scores were converted to percentiles and ranked into 4 grades to allow comparison between the two checklists. Gwet's AC1 coefficient was used for interrater reliability assessment.

Results: The 97 included SRs had a wide range of methodological quality scores (AMSTAR median (IQR): 6 (5-8) vs. R-AMSTAR median (IQR): 30 (26-35)). The overall agreement score between the 2 raters was 0.62 ( $95 \% \mathrm{Cl} 0.39-0.86)$ for AMSTAR and 0.62 (95\% Cl 0.53-0.70) for R-AMSTAR. The 31 Cochrane systematic reviews (CSRs) were consistently ranked higher than the 66 non-Cochrane systematic reviews (NCSRs). The analysis of individual domains showed the best compliance in a comprehensive literature search (item 3) on both checklists. The results for the domain that was the least compliant differed: conflict of interest (item 11) was the item most poorly reported on AMSTAR vs. publication bias assessment (item 10) on R-AMSTAR. A high positive correlation between the total AMSTAR and R-AMSTAR scores for all SRs, as well as for CSRs and NCSRs, was observed.

Conclusions: The methodological quality of analyzed SRs in the field of NeuP was not optimal, and CSRs had a higher quality than NCSRs. Both AMSTAR and R-AMSTAR tools produced comparable quality ratings. Our results point out to weaknesses in the methodology of existing SRs on interventions for the management NeuP and call for future improvement by better adherence to analyzed quality checklists, either AMSTAR or R-AMSTAR.
\end{abstract}

Keywords: Neuropathic pain, Systematic review, Methodological quality, AMSTAR, R-AMSTAR, Interrater reliability

\footnotetext{
*Correspondence: livia@mefst.hr

2 Laboratory for Pain Research, University of Split School of Medicine,

Soltanska 2, 21000 Split, Croatia

${ }^{6}$ Agency for Quality and Accreditation in Health Care and Social Welfare,

Zagreb, Croatia

Full list of author information is available at the end of the article
}

(c) The Author(s). 2018 Open Access This article is distributed under the terms of the Creative Commons Attribution 4.0 International License (http://creativecommons.org/licenses/by/4.0/), which permits unrestricted use, distribution, and reproduction in any medium, provided you give appropriate credit to the original author(s) and the source, provide a link to the Creative Commons license, and indicate if changes were made. The Creative Commons Public Domain Dedication waiver (http://creativecommons.org/publicdomain/zero/1.0/) applies to the data made available in this article, unless otherwise stated. 


\section{Background}

Systematic reviews (SRs) are considered to be of the highest quality in the hierarchy of evidence and are increasingly used for evidence-based decision making [1]. SRs should summarize the literature on a given topic using rigorous methodology. One of the standard features of SR methodology is the assessment of the quality of included primary studies, by using various tools [2].

However, there are also tools for assessing the methodological quality of SRs themselves, such as the Assessment of Multiple Systematic Reviews (AMSTAR), developed in 2007 [3]. AMSTAR was found to be a reliable and valid measurement tool for assessing the methodological quality of SRs [4]. A different group of authors suggested the use of revised AMSTAR (R-AMSTAR) in 2010 [5]. Despite the existence of R-AMSTAR, it was reported that AMSTAR had been used more frequently for the assessment of methodological quality of SRs [6]. This could be because AMSTAR, despite its flaws and many suggestions for its improvement, is shorter and simpler to use [7].

These tools for the assessment of methodological quality of SRs show that many SRs are inadequate. A comprehensive report on 300 SRs published in 2007 showed that their quality of reporting was inconsistent, indicating that readers should not think of SRs as synonymous with high-quality evidence [8]. An updated version of this study, published in 2016, indicated that the number of SRs being published is increasing, but the majority of them are still poorly conducted and reported [9].

Neuropathic pain (NeuP) has been estimated to affect $5-10 \%$ of the general population [10-12] and is associated with poor general health and quality of life [13-15]. This research area has received considerable attention from the International Association for the Study of Pain (IASP) as, despite the availability of many drugs and guidelines, NeuP remains under- or untreated in many cases [16]. Several evidence-based guidelines for the management of NeuP have been published in recent years [17-22]. It is of particular importance to ensure that those recommendations are based on high-quality research. It is also important to find out which measurement tool can be recommended for methodological quality rating in this cohort of interventional SRs.

Therefore, our primary aim was to analyze the methodological quality of SRs in the field of NeuP and to compare two different tools for quality assessment because it is still unclear which one is more appropriate. For this purpose, we used AMSTAR, a validated tool, and R-AMSTAR, which still cannot be put at the same level as AMSTAR with respect to validation. Our secondary aims were to calculate the interrater reliability and scoring discrepancies between the two authors and to analyze the overall agreement score between AMSTAR and R-AMSTAR. By assessing the methodological quality of available evidence, we hope to call attention to the current weaknesses of those tools and inspire future researchers to set higher standards in conducting SRs.

\section{Methods \\ Protocol registration}

We developed a protocol for this study a priori and registered it in the PROSPERO International Prospective Register of Systematic Reviews (registration number: CRD42015025832).

\section{Inclusion criteria}

We included SRs of randomized controlled trials (RCTs) evaluating efficacy and safety of any therapeutic intervention for NeuP according to the IASP definition [23]. Any comparator and any outcome measure were eligible for inclusion. Studies in any language were eligible.

\section{Exclusion criteria}

We excluded individual patient data SRs, SRs that were not interventional (e.g., prognostic, diagnostic accuracy), SRs that included other types of studies besides RCTs, as well as SRs that included a population with disorders that do not satisfy the current IASP criteria for NeuP [23]. We also excluded SRs published only as abstracts.

\section{Study selection}

We searched MEDLINE, Cochrane Database of Systematic Reviews, DARE, CINAHL and PsycINFO from the earliest date that each database allowed up to March 9, 2015, without language or publication date restriction. A comprehensive search strategy for MEDLINE (Additional file 1) was developed by combining medical subject heading (MeSH) terms and text words for NeuP conditions with text words for SR/meta-analysis. The MEDLINE strategy was adapted for other databases. Two authors (SD, AJK) independently screened the search results for inclusion using pre-defined relevance criteria at all levels of screening (e.g., title and abstract, full-text review of potentially relevant articles). Discrepancies were resolved by discussion and the involvement of a third author (LP).

\section{Assessment of methodological quality}

AMSTAR [24] and R-AMSTAR [5] were applied to all included SRs. We used a newer version of AMSTAR, with explanations available on the tool's website [24]. Before quality assessment, the items on both scales were discussed, and a calibration exercise was performed on one of the included SRs. Summary scores for AMSTAR (possible range 0-11) and R-AMSTAR (possible range 1144) were calculated by two independent junior research fellows (one clinician and one methodologist) experienced in methodological studies, but without formal experience with these tools (NM, KV). Raters without formal training in 
applying AMSTAR and R-AMSTAR were chosen because we did not want previous experience and potentially differing approaches to using AMSTAR and R-AMSTAR (due to ambivalence and multi-layer aspects of some domains) to influence the raters. In this way, the level of expertise of raters was removed as a potential confounding variable in rating the evidence. The AMSTAR tool was applied first to the whole set of included SRs. After approximately 46 weeks, the methodological quality rating was repeated with the R-AMSTAR tool. Discrepancies were resolved by the involvement of a third author (SD).

The performance of studies on each AMSTAR domain was rated by looking into the proportion of studies with a score "yes" compared to other possible scores, while the performance on each R-AMSTAR domain was assessed by looking into the percentage of studies with highest scores (scores 4 and 3), with 4 as the maximum score for a domain in R-AMSTAR. A subgroup analysis was made for the differences in methodological quality between Cochrane SRs (CSRs) and non-Cochrane SRs (NCSRs).

\section{Comparison of AMSTAR and R-AMSTAR}

The AMSTAR and R-AMSTAR scores of each SR were subsequently converted to percentiles for each checklist to allow for the comparison of quality scores between the different assessment tools. We calculated percentiles by first ranking quality scores from lowest to highest and then taking the value from the ordered list that corresponds to that rank. The percentiles were assigned surrogate grades, as follows: grade A: $\geq 90 \%$ ile, grade B: $80-89 \%$ ile, grade C: $70-79 \%$ ile, grade D: $\leq 69 \%$ ile, as described previously [5]. Based on the resulting percentile scores, surrogate grades were assigned to each SR. Both total scores and surrogate grades were compared between the two assessment tools.

\section{Interrater agreement}

We analyzed the interrater agreement by using Gwet's AC1 coefficient [25]. An overall agreement score, as well as a score for each item, was calculated. We also calculated Cohen's Kappa values and presented the results in Additional file 2 (AMSTAR) and Additional file 3 (RAMSTAR). Values were calculated for AMSTAR by dichotomizing the responses into the categories "yes" (1 point) versus any other score ("no", "can't answer", "not applicable"; each 0 points). For R-AMSTAR we calculated the interrater agreement on all the criteria in each of the 11 questions, resulting in a total of 41 assessments. The possible responses were "yes" or "no". A study used for calibration exercise was excluded from the calculation [26].

For simplification, we interpreted both interrater agreement measures, Gwet's AC1 coefficient and Cohen's Kappa, as follows: coefficients of less than 0 signify poor agreement; $0.01-0.20$ slight agreement; $0.21-0.40$ fair agreement; $0.41-0.60$ moderate agreement; $0.61-0.80$ substantial agreement; and 0.81-0.99 almost perfect agreement, as proposed by Landis and Koch [27]. However, we need to emphasize that this categorization was originally proposed based on Cohen's Kappa values only.

\section{Data analysis}

The data about the performance of SRs on individual AMSTAR and R-AMSTAR domains were presented descriptively as frequencies and percentages. We presented methodological summary scores using median and interquartile range (IQR). Spearman rank correlation was performed to assess the association between total AMSTAR and R-AMSTAR scores.

We used IBM SPSS Statistics for Windows, version 19. 0.0 (IBM Corp., Armonk, N.Y., USA) and R statistical software and available script files [28] for performing analyses. Statistical significance was defined at $P<0.05$, two-tailed.

\section{Results}

Ninety-seven SRs were included. Table 1 presents a summary description of the included SRs. The references of included studies are presented in Additional file 4, the list of excluded studies in Additional file 5, and the study selection process in Fig. 1.

\section{Methodological quality and adherence to individual AMSTAR and R-AMSTAR domains}

The quality ratings of 97 included SRs are presented in Additional file 6 (AMSTAR) and Additional file 7 (R-AMSTAR). The median score was 6 (IQR: 5-8) on AMSTAR and 30 (IQR: 26-35) on R-AMSTAR.

A comparable quality rating was found based on surrogate grades assigned for AMSTAR and R-AMSTAR (Table 2). The lowest grade $\mathrm{D}$ was assigned to the majority of included NeuP SRs (64 based on AMSTAR vs. 68 based on R-AMSTAR assessment).

Studies scored best on AMSTAR items 3 (comprehensive literature search, 98\% fulfilled), 7 (scientific quality assessed and documented, 89\% fulfilled), and 9 (methods used to combine the findings appropriate, $80 \%$ fulfilled); and worst on items 11 (conflict of interest included, $12 \%$ fulfilled), 1 ('a priori' design provided, 35\% fulfilled) and 10 (likelihood of publication bias assessed, $40 \%$ fulfilled) (Fig. 2).

When R-AMSTAR was applied (Fig. 3), the best adherence was found for items 3 (comprehensive literature search, $86 \%$ of SRs with 4 points), and 2 (duplicate study selection and data extraction, $62 \%$ of SRs with 4 points); while the worst adherence was found for items 10 (likelihood of publication bias assessed, 49\% of SRs with 1 point), and 8 (scientific quality of the included studies used appropriately in formulating conclusions, $44 \%$ of SRs with 1 point). 
Table 1 Summary characteristics of 97 included systematic reviews

\begin{tabular}{|c|c|}
\hline Characteristic & $\mathrm{N}$ of SRs \\
\hline \multicolumn{2}{|l|}{ Year } \\
\hline $1995-2000$ & 4 \\
\hline $2001-2005$ & 10 \\
\hline 2005-2010 & 27 \\
\hline $2011-2015$ & 56 \\
\hline \multicolumn{2}{|l|}{ Number of authors } \\
\hline 1 & 1 \\
\hline $2-5$ & 72 \\
\hline $6-10$ & 23 \\
\hline$>10$ & 1 \\
\hline \multicolumn{2}{|c|}{ Language of the studies included in SRs } \\
\hline Any language & 49 \\
\hline English & 30 \\
\hline English plus other & 18 \\
\hline Not reported & 6 \\
\hline \multicolumn{2}{|l|}{ Language of SRs } \\
\hline English & 91 \\
\hline Chinese & 2 \\
\hline French & 1 \\
\hline German & 1 \\
\hline Spanish & 1 \\
\hline Portuguese and English & 1 \\
\hline \multicolumn{2}{|l|}{ Number of RCTs included } \\
\hline $0-1$ & 8 \\
\hline $2-10$ & 37 \\
\hline $11-20$ & 30 \\
\hline $21-30$ & 14 \\
\hline $31-40$ & 4 \\
\hline $41-100$ & 3 \\
\hline$>100$ & 1 \\
\hline \multicolumn{2}{|c|}{ Number of databases searched } \\
\hline 1 & 1 \\
\hline $2-3$ & 27 \\
\hline $4-5$ & 38 \\
\hline$>6$ & 31 \\
\hline \multicolumn{2}{|l|}{ Neuropathic pain type } \\
\hline Peripheral & 86 \\
\hline Central & 2 \\
\hline Peripheral and central & 9 \\
\hline \multicolumn{2}{|l|}{ Total number of patients } \\
\hline 0 & 7 \\
\hline $1-1000$ & 28 \\
\hline $1001-2000$ & 28 \\
\hline
\end{tabular}

Table 1 Summary characteristics of 97 included systematic reviews (Continued)

\begin{tabular}{|c|c|}
\hline Characteristic & $\mathrm{N}$ of SRs \\
\hline $2001-4000$ & 14 \\
\hline$>4001$ & 12 \\
\hline Unclear & 8 \\
\hline \multicolumn{2}{|l|}{ Meta-analysis } \\
\hline Yes & 65 \\
\hline No & 25 \\
\hline Not applicable (empty review) & 7 \\
\hline \multicolumn{2}{|l|}{ Update of previous SR } \\
\hline Yes & 10 \\
\hline No & 87 \\
\hline \multicolumn{2}{|l|}{ Number of updates } \\
\hline 1 & 7 \\
\hline $2-3$ & 2 \\
\hline$>4$ & 1 \\
\hline \multicolumn{2}{|l|}{ Funding source } \\
\hline Not reported & 35 \\
\hline No external funding & 13 \\
\hline Government & 12 \\
\hline Foundation & 12 \\
\hline None & 11 \\
\hline Industry & 8 \\
\hline Multiple & 6 \\
\hline
\end{tabular}

$S R$ systematic review, $R C T$ randomized controlled trial

\section{Methodological quality of Cochrane systematic reviews (CSRs)}

The median number of fulfilled items in 31 CSRs was 9 (IQR: 8-10) of 11 on AMSTAR and 37 (IQR: 33-40) of 44 maximum possible R-AMSTAR items.

When surrogate grades were assigned, the majority of CSRs were rated as grade A on AMSTAR $(N=14)$ and R-AMSTAR $(N=11)$. The distribution of other grades was also similar (Table 2).

All CSRs scored "yes" on AMSTAR items 1 ('a priori' design provided) and 3 (comprehensive literature search), and 30 on item 2 (duplicate study selection and data extraction) (Fig. 4). Similar results were found for R-AMSTAR: all CSRs scored 4 points on item 1,30 on item 3 , and 27 on item 2 (Fig. 5).

The worst compliance for CSRs was on AMSTAR item 11, with 18 studies that did not include conflict of interest in both the SR and the included studies (Fig. 4). On R-AMSTAR (Fig. 5), the domains with the poorest performance were domains 9 (appropriate methods used to combine the findings of studies), 10 (likelihood of publication bias assessed), and 8 (scientific quality appropriately used in formulating conclusions). 


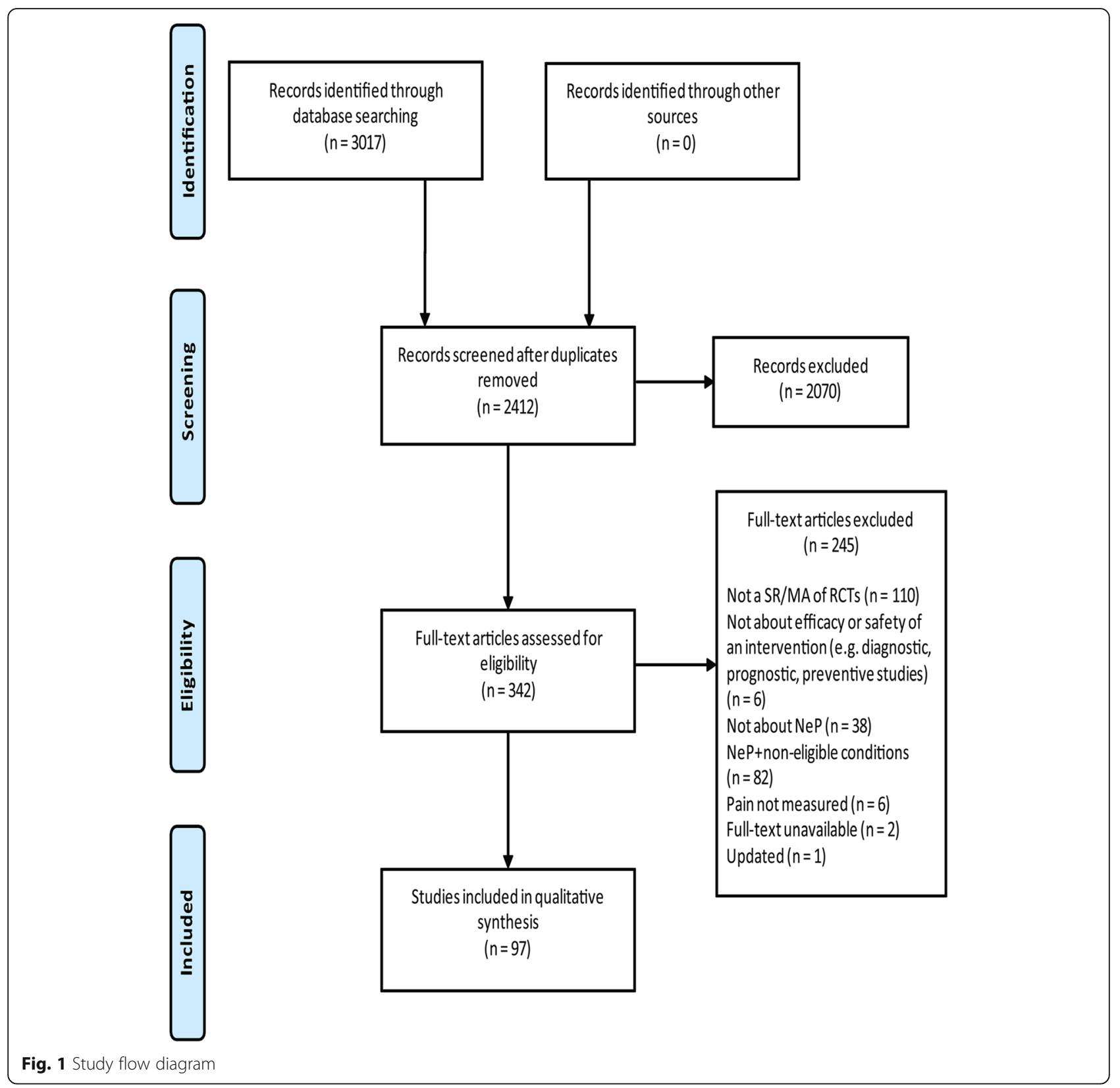

Table 2 Quality of all reviews, Cochrane and non-Cochrane systematic reviews according to AMSTAR and R-AMSTAR percentile scores

\begin{tabular}{|c|c|c|c|c|c|c|}
\hline \multirow[b]{2}{*}{ Grade } & \multicolumn{2}{|l|}{ All SRs } & \multicolumn{2}{|l|}{ Cochrane SRs } & \multicolumn{2}{|c|}{ Non-Cochrane SRs } \\
\hline & AMSTAR N (\%) & R-AMSTAR N (\%) & AMSTAR N (\%) & R-AMSTAR N (\%) & AMSTAR N (\%) & R-AMSTAR N (\%) \\
\hline A & $14(14)$ & $11(11)$ & $14(45)$ & $11(36)$ & $0(0)$ & $0(0)$ \\
\hline B & $9(9)$ & $9(9)$ & $6(19)$ & $6(19)$ & $3(5)$ & $3(5)$ \\
\hline C & $10(10)$ & $9(9)$ & $4(13)$ & $4(13)$ & $6(9)$ & $5(8)$ \\
\hline D & $64(66)$ & $68(70)$ & $7(23)$ & $10(32)$ & $57(86)$ & $58(88)$ \\
\hline Total & $97(100)$ & $97(100)$ & $31(100)$ & $31(100)$ & $66(100)$ & $66(100)$ \\
\hline
\end{tabular}

Quality grades assigned according to percentiles (Grade A: $\geq 90 \%$ ile, Grade B: $80-89 \%$ ile, Grade C: $70-79 \%$ ile, Grade D: $\leq 69 \%$ ile)

AMSTAR Assessment of Multiple Systematic Reviews checklist, R-AMSTAR a revised version of AMSTAR checklist, SR systematic review 


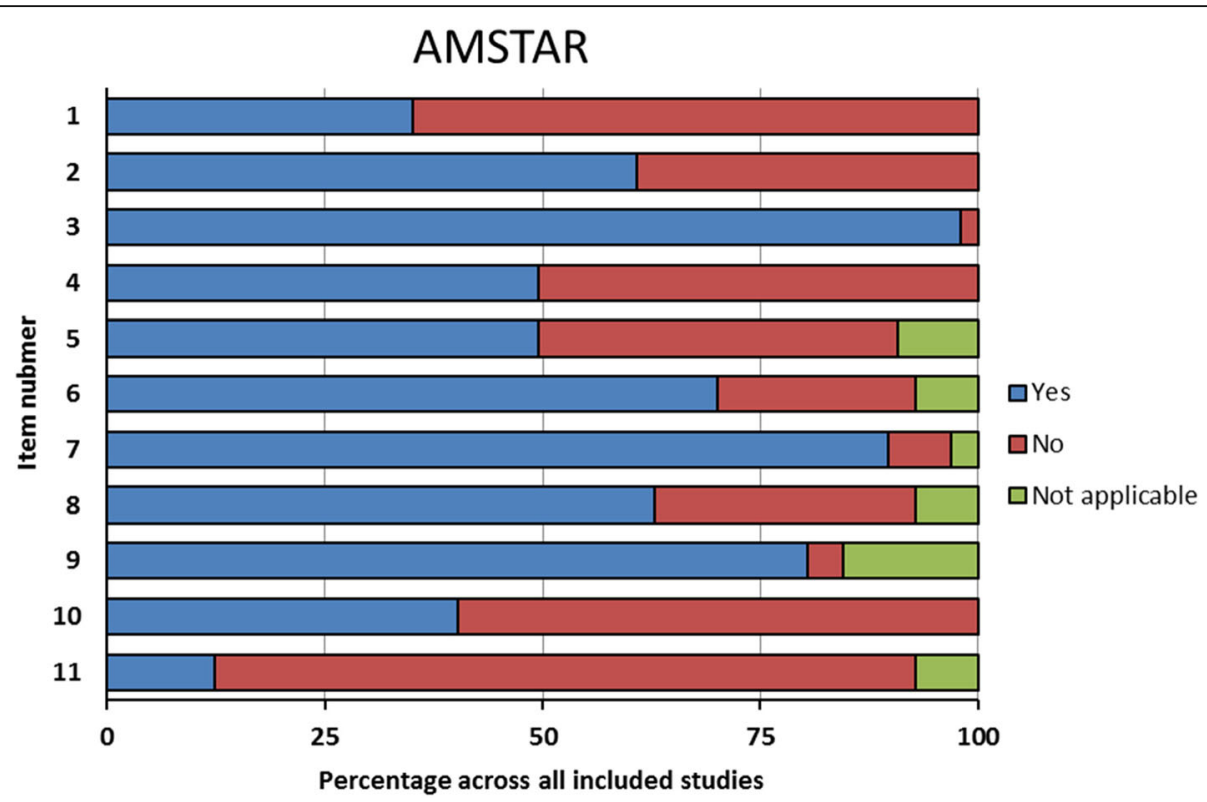

Fig. 2 Quality of all included systematic reviews by AMSTAR domain

\section{Methodological quality of non-Cochrane systematic reviews (NCSRs)}

The 66 NCSRs fulfilled a median of 6 (IQR: 5-7) of 11 possible items on AMSTAR and 29 (IQR: 25-32) of maximum 44 items on R-AMSTAR.

As shown in Table 2, none of the NCSRs reached grade $\mathrm{A}$, while the majority received grade $\mathrm{D}$ on both AMSTAR $(N=57)$ and R-AMSTAR $(N=58)$. Grading based on the AMSTAR and R-AMSTAR scores yielded almost identical numbers of grade B and C NCSRs.

The NCSRs showed the best compliance with items 3 (comprehensive literature search), 7 (scientific quality of the included studies assessed and documented), and 9 (methods used to combine the findings of studies appropriate) on both AMSTAR (Fig. 6) and R-AMSTAR (Fig. 7). The poorest performing domains on AMSTAR were items

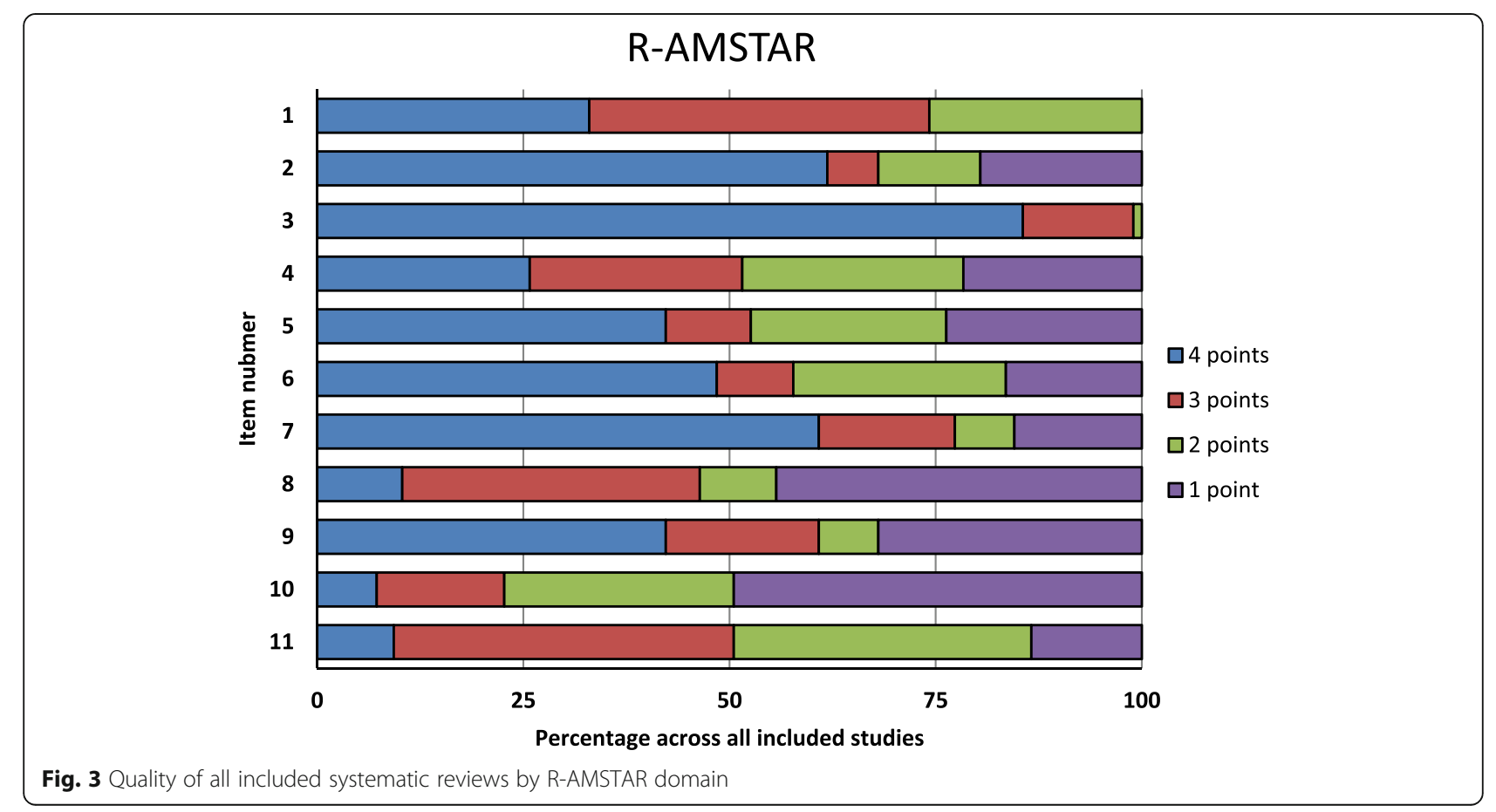




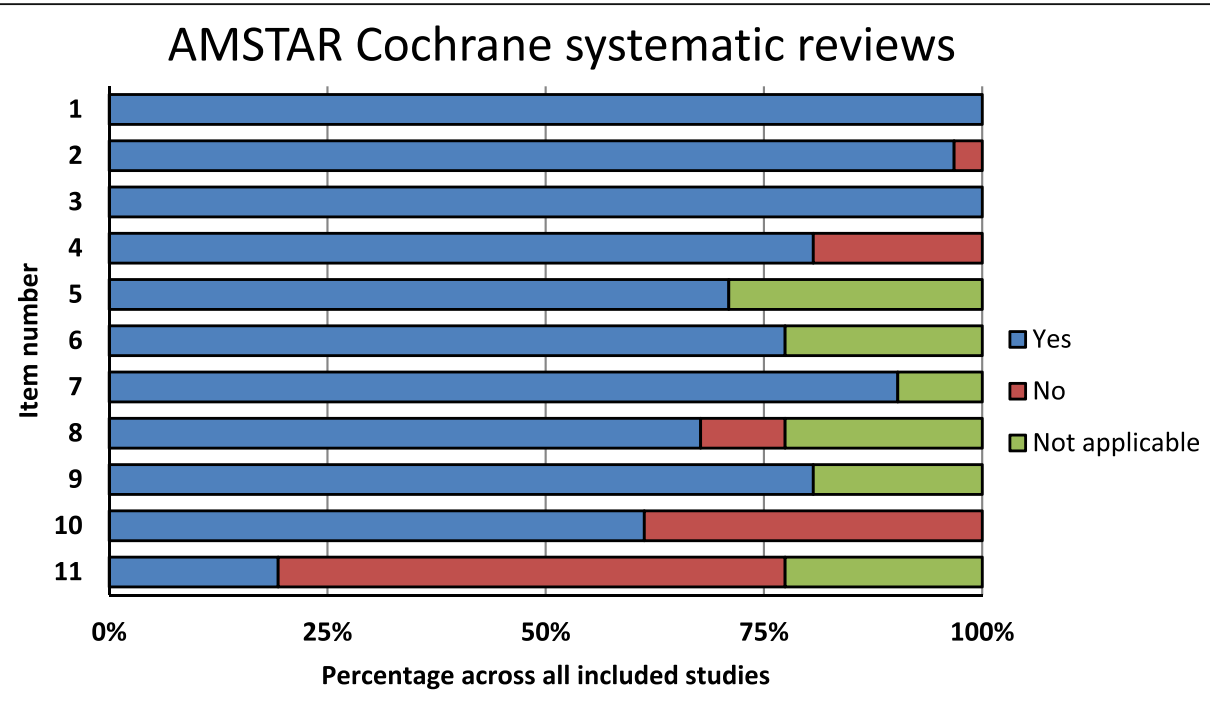

Fig. 4 Quality of Cochrane systematic reviews by AMSTAR domain

1 ('a priori' design provided) and 11 (conflict of interest included), with more than $90 \%$ of studies that did not fulfill criteria for a "yes" score (Fig. 6). Figure 7 shows the poorest performing domains on R-AMSTAR: items 10 (likelihood of publication bias assessed) and 8 (scientific quality of the included studies used appropriately in formulating conclusions).

\section{Comparison of methodological quality of Cochrane and} non-Cochrane systematic reviews

The quality ratings of 97 SRs expressed in percentiles were similar between AMSTAR (median 47.94, IQR 27. 84-71.13) and R-AMSTAR (median 50, IQR 26.3-74.2). Cochrane SRs consistently scored higher than NCSRs, and similar ratings were obtained using both AMSTAR (CSRs median (IQR): 80.93 (71.13-90.72) vs. NCSRs median (IQR): 47.94 (27.84-61.86)) and R-AMSTAR (CSRs median (IQR): 83 (61.3-92.15) vs. NCSRs median (IQR): $42.3(20.1-57.7))$.

\section{Correlation of AMSTAR and R-AMSTAR ratings}

We found significant high positive correlation between the AMSTAR and R-AMSTAR scores for all analyzed SRs (Spearman's rho $=0.88,95 \%$ CI $0.83-0.92 ; P<0.001$ ), as well as for CSRs (Spearman's rho $=0.82,95 \%$ CI 0 . 65-0.91; $P<0.001)$ and NCSRs (Spearman's rho $=0.75$, 95\% CI 0.61-0.84; $P<0.001)$.

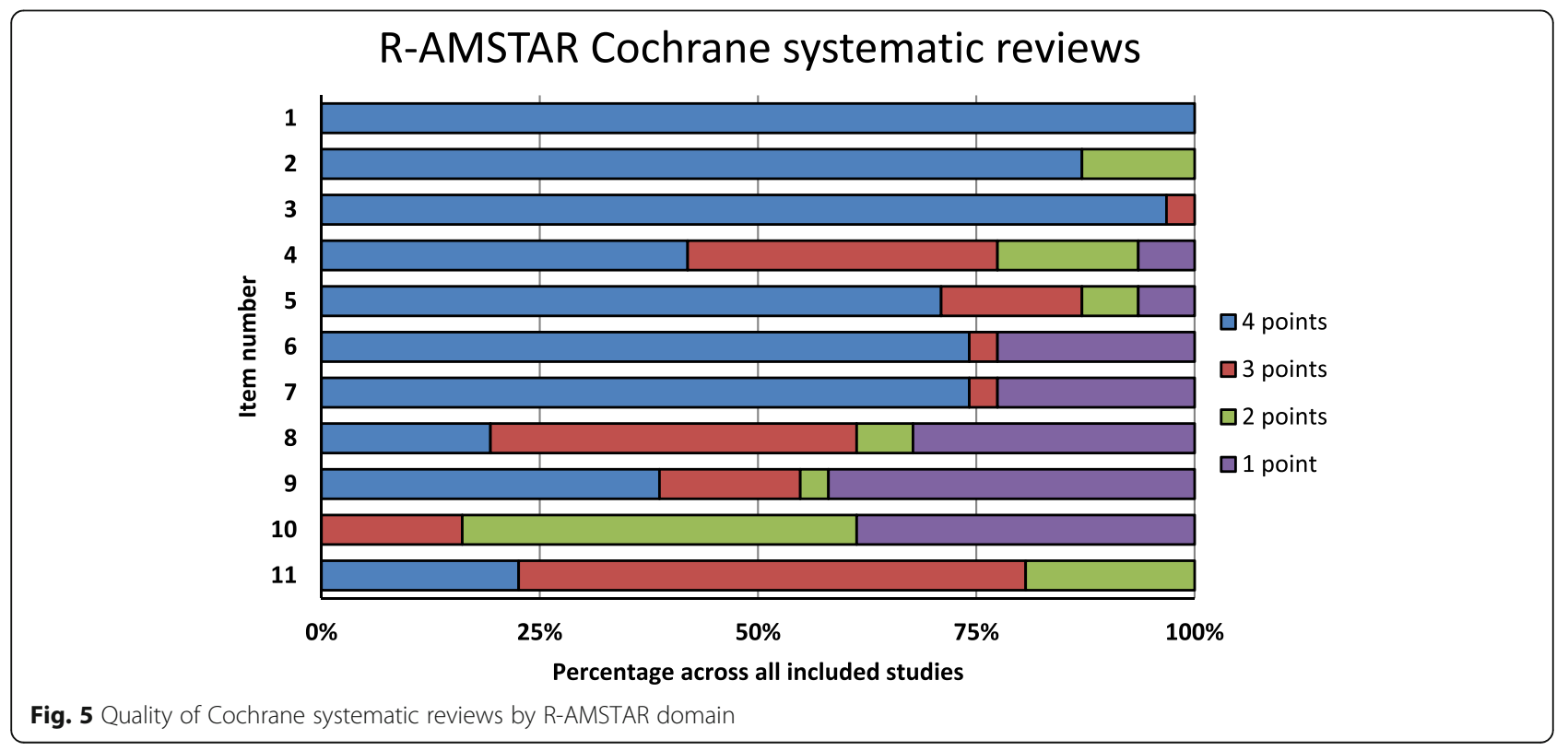




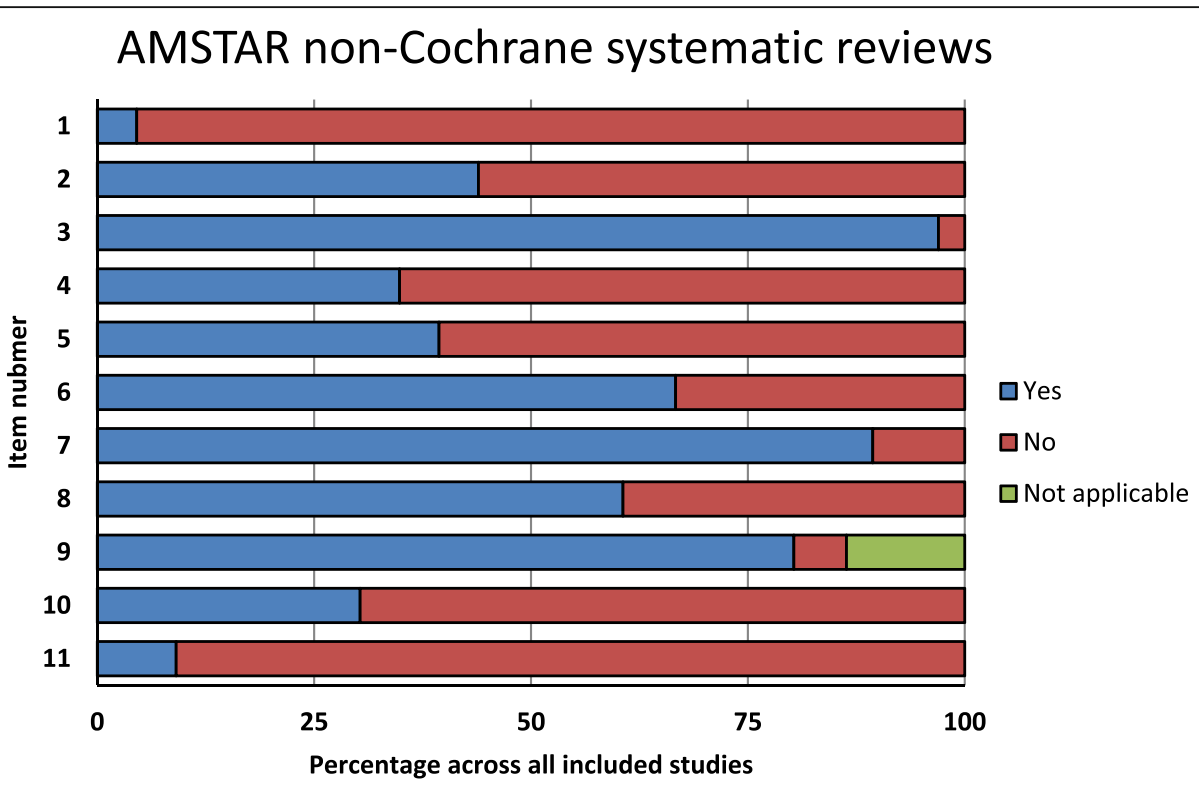

Fig. 6 Quality of non-Cochrane systematic reviews by AMSTAR domain

\section{Interrater agreement}

The levels of agreement between the 2 raters on both tools ranged from poor to almost perfect. The overall agreement score was substantial for both AMSTAR (Gwet's $\mathrm{AC} 1=0.62,95 \% \mathrm{CI} 0.39-0.86$ ) and R-AMSTAR (Gwet's $\mathrm{AC} 1=0.62,95 \% \mathrm{CI}$ 0.53-0.70). Detailed interrater agreement scores for all items on AMSTAR and RAMSTAR are presented in Tables 3 and 4, respectively.

Four AMSTAR domains reached almost perfect Gwet's AC1 values: 'a priori' design of the research question (item 1), comprehensive literature search (item 3), assessment of the scientific quality of the included studies (item 7), and the use of appropriate methods for combining the findings of studies (item 9). On the other hand, poor agreement was observed when raters judged whether the status of publication was used as an inclusion criterion (item 4) and if the characteristics of the included studies were provided (item 6).

Based on Gwet's AC1 values, items 3, 7, 10 (publication bias assessment) and 11 (information about conflict of interest) had the highest average Gwet's AC1 coefficients $(\geq 0.7)$, and item 4 the lowest $(0.31)$ on R-AMSTAR.

The assessment of the fulfillment of individual criteria within each R-AMSTAR item showed that poor agreement

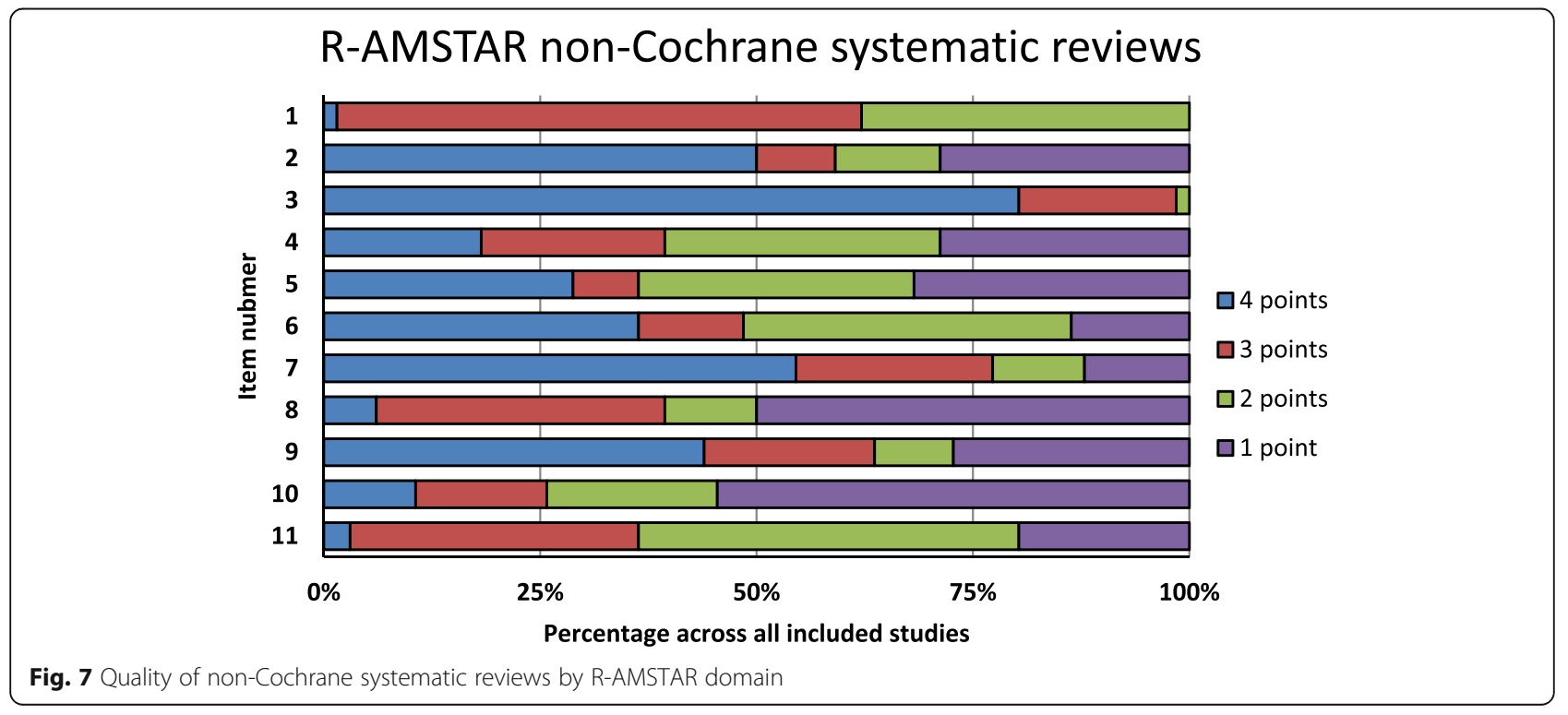


Table 3 Interrater agreement for AMSTAR

\begin{tabular}{|c|c|c|c|}
\hline Item & Gwet's AC1 & SEM & $95 \% \mathrm{Cl}$ \\
\hline 1. Was an 'a priori' design provided & 0.90 & 0.04 & $0.82-0.99$ \\
\hline 2. Was there duplicate study selection and data extraction & 0.47 & 0.09 & $0.29-0.66$ \\
\hline 3. Was a comprehensive literature search performed & 0.92 & 0.03 & $0.85-0.98$ \\
\hline 4. Was the status of publication (i.e. grey literature) used as an inclusion criterion & 0.03 & 0.11 & $-0.19-0.24$ \\
\hline 5. Was a list of studies (included and excluded) provided & 0.63 & 0.08 & $0.47-0.79$ \\
\hline 6. Were the characteristics of the included studies provided & -0.09 & 0.10 & $-0.30-0.12$ \\
\hline 7. Was the scientific quality of the included studies assessed and documented & 0.89 & 0.04 & $0.81-0.97$ \\
\hline 8. Was the scientific quality of the included studies used appropriately in formulating conclusions & 0.68 & 0.08 & $0.53-0.83$ \\
\hline 9. Were the methods used to combine the findings of studies appropriate & 0.88 & 0.04 & $0.79-0.96$ \\
\hline 10. Was the likelihood of publication bias assessed & 0.76 & 0.07 & $0.62-0.89$ \\
\hline 11. Was the conflict of interest included & 0.80 & 0.05 & $0.70-0.91$ \\
\hline Overall agreement (mean score of 11 items) & 0.62 & 0.10 & $0.39-0.86$ \\
\hline
\end{tabular}

AMSTAR Assessment of Multiple Systematic Reviews checklist, SEM standard error of the mean, Cl confidence interval

was achieved for criteria 4B (statement of exclusion of any reports based on the publication status, language, etc.) and $1 \mathrm{~A}$ ('a priori' design provided).

Almost perfect agreement (Gwet's AC1 0.81-1.00) was observed for criteria 1B (statement of inclusion criteria), 3A (at least two electronic sources searched); 3B (reporting years and databases searched), 3E (manual journal search), 5A (Table/list/or figure of included studies provided), 7A ('a priori' methods of assessment of scientific quality provided), 8D (whether clinical consensus statement drives toward revision or confirmation of clinical practice guidelines), $10 \mathrm{C}$ (statistical tests for publication bias assessment), and 11C (conflict of interest assessed in included studies).

\section{Discussion}

We found that the methodological quality of analyzed SRs published in the field of NeuP was not optimal. When we compared AMSTAR and R-AMSTAR, we found that, overall, both tools produced comparable quality ratings of the included NeuP SRs.

Several previous studies that focused only on the methodological quality of SRs in other fields of pain used AMSTAR. For example, Martinis et al. assessed the quality of 40 SRs about surgical treatment of low back pain. They reported that $5 \%$ of SRs were of excellent quality, most were of fair quality, and $22.5 \%$ of poor quality [29]. Song et al. analyzed the methodological quality of 17 SRs on the effectiveness of non-pharmacological cancer pain management and found that only 1 SR was of high quality, while five were of low quality. The mean AMSTAR score was 5.47, indicating overall moderate quality [30]. We could not find any studies that focused only on methodological quality in the field of pain that used R-AMSTAR, and none that compared the use of the 2 measurement tools.
A recent SR of Pieper et al. found that AMSTAR had good measurement properties, but R-AMSTAR did not [31]. Pieper et al. searched four databases to analyze reliability, validity, and feasibility of the AMSTAR and RAMSTAR. They included 9 studies that analyzed AMSTAR, two studies that analyzed R-AMSTAR, and one article that analyzed both tools. The authors of that SR did not provide any methodological details about calculating interrater reliability for R-AMSTAR because the studies using R-AMSTAR did not report them either [31].

Without any guidance for calculating interrater reliability in the R-AMSTAR, and led by the findings from a study by Wongpakaran et al. that showed Gwet's AC1 coefficient was a more stable interrater reliability measure than Cohen's Kappa in personality disorder samples [32], we decided to use Gwet's AC1 in our study. However, we have to take into account that the interpretation of reliability measures by Landis and Koch was originally published for measures of Cohen's Kappa and it might not be fully applicable for Gwet's AC1 coefficients. Compared to Cohen's Kappa, Gwet's AC1 values tend to be higher [32].

Our results showed poor agreement for AMSTAR item 4 (status of publication was used as an inclusion criterion) and 6 (characteristics of the included studies). Low interrater reliability using Cohen's Kappa coefficient has been previously reported for item 4 , and the study mentioned difficulties in applying the publication status item [4].

Findings from a 2015 SR by Pieper et al., based on results from 6 studies, also showed the lowest median interrater reliability using Cohen's Kappa for AMSTAR item 6 (characteristics of the included studies) [31]. Other items with lowest median interrater reliability scores (indicating substantial agreement) were item 8 (scientific quality appropriately used in formulating conclusions) and 5 (list of included and excluded studies), which is in accordance with our interrater reliability measures. The highest interrater 
Table 4 Interrater agreement for R-AMSTAR

\begin{tabular}{|c|c|c|c|c|}
\hline Item & Criterion & Gwet's AC1 & SEM & $95 \% \mathrm{Cl}$ \\
\hline \multirow[t]{3}{*}{ 1. Was an 'a priori' design provided } & A & 0.02 & 0.11 & $-0.20-0.24$ \\
\hline & B & 0.93 & 0.03 & $0.88-0.99$ \\
\hline & C & 0.34 & 0.10 & $0.15-0.54$ \\
\hline \multirow[t]{3}{*}{ 2. Was there duplicate study selection and data extraction } & A & 0.78 & 0.06 & $0.66-0.90$ \\
\hline & B & 0.64 & 0.08 & $0.48-0.79$ \\
\hline & C & 0.62 & 0.08 & $0.45-0.78$ \\
\hline \multirow[t]{5}{*}{ 3. Was a comprehensive literature search performed } & A & 0.97 & 0.02 & $0.93-1.00$ \\
\hline & B & 0.94 & 0.03 & $0.89-0.99$ \\
\hline & C & 0.25 & 0.11 & $0.03-0.47$ \\
\hline & $\mathrm{D}$ & 0.55 & 0.09 & $0.38-0.73$ \\
\hline & E & 0.83 & 0.05 & $0.73-0.93$ \\
\hline \multirow[t]{4}{*}{ 4. Was the status of publication (i.e. grey literature) used as an inclusion criterion } & A & 0.55 & 0.09 & $0.38-0.72$ \\
\hline & B & -0.32 & 0.10 & $-0.52-(-0.12)$ \\
\hline & C & 0.24 & 0.10 & $0.04-0.44$ \\
\hline & $\mathrm{D}$ & 0.75 & 0.07 & $0.61-0.88$ \\
\hline \multirow[t]{4}{*}{ 5. Was a list of studies (included and excluded) provided } & A & 0.95 & 0.02 & $0.89-1$ \\
\hline & B & 0.79 & 0.06 & $0.67-0.92$ \\
\hline & C & 0.41 & 0.10 & $0.21-0.60$ \\
\hline & $\mathrm{D}$ & 0.48 & 0.09 & $0.30-0.66$ \\
\hline \multirow[t]{3}{*}{ 6. Were the characteristics of the included studies provided } & A & 0.79 & 0.06 & $0.68-0.91$ \\
\hline & B & 0.46 & 0.09 & $0.28-0.64$ \\
\hline & C & 0.60 & 0.08 & $0.43-0.76$ \\
\hline \multirow[t]{4}{*}{ 7. Was the scientific quality of the included studies assessed and documented } & A & 0.86 & 0.04 & $0.77-0.95$ \\
\hline & B & 0.66 & 0.08 & $0.50-0.81$ \\
\hline & C & 0.61 & 0.08 & $0.45-0.78$ \\
\hline & $\mathrm{D}$ & 0.73 & 0.07 & $0.59-0.86$ \\
\hline \multirow[t]{4}{*}{ 8. Was the scientific quality of the included studies used appropriately in formulating conclusions } & A & 0.66 & 0.08 & $0.50-0.81$ \\
\hline & B & 0.23 & 0.10 & $0.03-0.43$ \\
\hline & C & 0.28 & 0.10 & $0.07-0.48$ \\
\hline & $\mathrm{D}$ & 0.97 & 0.02 & $0.93-1$ \\
\hline \multirow[t]{5}{*}{ 9. Were the methods used to combine the findings of studies appropriate } & A & 0.71 & 0.07 & $0.57-0.85$ \\
\hline & B & 0.74 & 0.07 & $0.60-0.88$ \\
\hline & C & 0.68 & 0.08 & $0.53-0.83$ \\
\hline & $\mathrm{D}$ & 0.67 & 0.08 & $0.52-0.82$ \\
\hline & $\mathrm{E}$ & 0.47 & 0.10 & $0.28-0.66$ \\
\hline \multirow[t]{3}{*}{ 10. Was the likelihood of publication bias assessed } & A & 0.58 & 0.08 & $0.41-0.74$ \\
\hline & B & 0.80 & 0.06 & $0.69-0.92$ \\
\hline & C & 0.95 & 0.03 & $0.90-1$ \\
\hline \multirow[t]{3}{*}{ 11. Was the conflict of interest included } & A & 0.70 & 0.07 & $0.56-0.84$ \\
\hline & B & 0.60 & 0.08 & $0.44-0.76$ \\
\hline & C & 0.85 & 0.05 & $0.76-0.95$ \\
\hline Overall agreement (mean score of 41 items) & & 0.62 & 0.04 & $0.53-0.70$ \\
\hline
\end{tabular}

R-AMSTAR, a revised version of Assessment of Multiple Systematic Reviews checklist, SEM standard error of the mean, $\mathrm{Cl}$ confidence interval 
reliability scores (almost perfect agreement) in the study of Pieper et al. were reported for item 10 (publication bias assessment) and 11 (conflicts of interest stated); those items reached substantial agreement on our sample of 97 SRs [31].

The raters reached substantial agreement on 4 of our RAMSTAR items with the highest average Gwet's AC1 values (items 3, 7, 10, 11). Compared to Cohen's Kappa values obtained in an SR in subfertility [33], only item 10 in their study had a higher interrater reliability.

For R-AMSTAR we calculated the interrater agreement on 41 items by taking into account all the criteria (from 3 (A-C) to 5 criteria (A-E)) in each of the 11 items. We cannot correctly judge whether the raters agree that the same criteria are fulfilled (e.g., rater 1: A and $\mathrm{B}$; rater 2: C and D) solely by looking into the 11item based agreement. Our results indicate the most problematic individual criteria within each R-AMSTAR item where our raters obtained poor agreement; they are the statement of exclusion of any reports based on the publication status, language, etc. (criterion 4B) and 'a priori' design provided (criterion 1A). These items would particularly benefit from further clarification on how to apply them.

We also confirmed in our sample of NeuP interventional SRs that CSRs have a higher methodological quality compared to NCSRs: the majority of CSRs had scores above the 80th percentile, compared to NCSRs where the majority scored in the lowest category. A number of studies from different research fields have previously shown that the quality of CSRs is superior [4, 8, 34-36]. However, we did not find a difference in correlation measures between AMSTAR and R-AMSTAR depending on whether it is a Cochrane review or not. In the study of Popovich et al., a much higher correlation between AMSTAR and R-AMSTAR was found for NCSRs than for CSRs in the field of subfertility. These results warrant further studying [31].

In order to improve the methodological quality of SRs, a joint action by SR authors, peer reviewers, and editors is needed. When planning and reporting their SR, the authors should follow a relevant checklist to ensure that the manuscript has appropriate methodological quality. Peer reviewers should analyze SRs against the relevant checklist, and editors could endorse methodological quality tools for specific article types and require authors to adhere to them. Editors are gatekeepers who can make sure the authors adhere to expected submission criteria. A recent editorial described that one journal is beginning this process: inspired by the findings of a study that showed poor and stagnating methodological quality of SRs in the field of urology [37], the BJU International decided to request from all SR authors to submit an AMSTAR checklist together with the manuscript, which will be utilized as part of the editorial and peerreview process [38].

A limitation of this study is that we have included SRs published since 1995, while AMSTAR was only published in 2007. It is possible that the methodological quality of SRs has increased since the introduction of AMSTAR since there is already some evidence that might support this [39-42]. Another limitation of this study is that calculating AMSTAR scores in this way implies that each item has the same weight. This assumption might be wrong because not all the domains of AMSTAR should have the same methodological value.

It is also possible that the differences observed between interrater agreement results obtained in ours and other studies might be influenced by the experience of the raters [43], although this is difficult to judge since rater experience is not frequently reported in the included studies [31]. We believe that both tools could be easily applied by an untrained person after a thorough discussion of the items and a calibration exercise before assessment, as we did.

Future studies should also include an assessment of ROBIS, a new tool for assessing the risk of bias in SRs, which was published in 2016 [44]. Likewise, the development of AMSTAR 2 was announced at the 2016 Cochrane Colloquium [45], so new studies about the updated tool are warranted once it is published.

\section{Conclusion}

In conclusion, since both AMSTAR and R-AMSTAR tools produced comparable quality ratings of the included SRs, we advise future use of AMSTAR because it is shorter and it has been shown to have good measurement properties in previous studies, unlike R-AMSTAR. Our analysis indicated that the methodological quality of existing SRs about interventions for the management NeuP is suboptimal, which calls for improvement by better adherence to methodological quality criteria.

\section{Additional files}

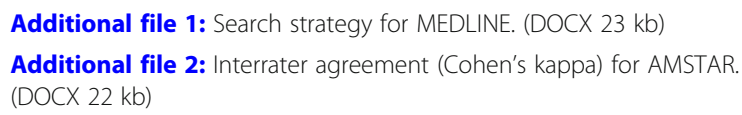

Additional file 3: Interrater agreement (Cohen's kappa) for R-AMSTAR. (DOCX $28 \mathrm{~kb}$ )

Additional file 4: References of included studies. (DOCX $139 \mathrm{~kb}$ )

Additional file 5: List of excluded studies with reasons. (DOCX 296 kb)

Additional file 6: AMSTAR rating for each study. (DOCX $211 \mathrm{~kb}$ )

Additional file 7: R-AMSTAR rating for each study. (DOCX $221 \mathrm{~kb}$ )

\section{Abbreviations}

AC1: Gwet's AC1 interrater agreement coefficient; AMSTAR: The Assessment of Multiple Systematic Reviews; CSR: Cochrane systematic review;

IASP: International Association for the Study of Pain; IQR: Interquartile range; 
MeSH: Medical Subject Headings; NCSR: Non-Cochrane systematic review; NeuP: Neuropathic pain; PROSPERO: International prospective register of systematic reviews; R-AMSTAR: Revised AMSTAR; RCT: Randomized controlled trial; ROBIS: Tool to assess risk of bias in systematic reviews; SR: Systematic review

\section{Acknowledgments}

The study was conducted within the project "Treating neuropathic pain with dorsal root ganglion stimulation" (HRZZ-IP-2013-11-4126) awarded to Professor Damir Sapunar by the Croatian Science Foundation (HRZZ). Even though the study was conducted within the project, the study did not receive any funding from the project. The HRZZ was not involved in any way in the design of the study, collection, analysis, interpretation of data or writing the manuscript. We are very grateful to Dalibora Behmen and Dora Vanette for language editing of the manuscript.

\section{Availability of data and materials}

The datasets used and/or analyzed during the current study are available from the corresponding author on reasonable request.

\section{Authors' contributions}

LP conceived the study design and helped to resolve discrepancies. AJK and SD independently screened and included eligible studies. KV and NM performed methodological quality assessments. DP and SD performed statistical analyses. SD drafted the manuscript with the help of LP. All authors were involved in critical revision of the manuscript, read and approved the final version of the manuscript, and have agreed to be accountable for all aspects of the work in ensuring that questions related to the accuracy or integrity of any part of the work are appropriately investigated and resolved.

\section{Ethics approval and consent to participate}

Not applicable.

\section{Competing interests}

The authors declare that they have no competing interests.

\section{Publisher's Note}

Springer Nature remains neutral with regard to jurisdictional claims in published maps and institutional affiliations.

\section{Author details}

'Department of Anesthesiology and Intensive Care Medicine, University Hospital Split, Split, Croatia. ${ }^{2}$ Laboratory for Pain Research, University of Split School of Medicine, Soltanska 2, 21000 Split, Croatia. ${ }^{3}$ Department of Pediatrics, University Hospital Split, Split, Croatia. ${ }^{4}$ Agency for Medicinal Products and Medical Devices, Zagreb, Croatia. ${ }^{5}$ Institute for Research in Operative Medicine (IFOM), Witten/Herdecke University, Cologne, Germany. ${ }^{6}$ Agency for Quality and Accreditation in Health Care and Social Welfare, Zagreb, Croatia.

\section{Received: 15 July 2017 Accepted: 16 April 2018}

\section{Published online: 08 May 2018}

\section{References}

1. Manchikanti L, Benyamin RM, Helm S, Hirsch JA. Evidence-based medicine, systematic reviews, and guidelines in interventional pain management: part 3: systematic reviews and meta-analyses of randomized trials. Pain Physician. 2009;12(1):35-72.

2. Seehra J, Pandis N, Koletsi D, Fleming PS. Use of quality assessment tools in systematic reviews was varied and inconsistent. J Clin Epidemiol. 69:179-84. e175

3. Shea BJ, Grimshaw JM, Wells GA, Boers M, Andersson N, Hamel C, Porter AC, Tugwell P, Moher D, Bouter LM. Development of AMSTAR: a measurement tool to assess the methodological quality of systematic reviews. BMC Med Res Methodol 2007; 7(1):10.

4. Shea BJ, Hamel C, Wells GA, Bouter LM, Kristjansson E, Grimshaw J, Henry DA, Boers M. AMSTAR is a reliable and valid measurement tool to assess the methodological quality of systematic reviews. J Clin Epidemiol. 2009;62(10):1013-20.

5. Kung J, Chiappelli F, Cajulis OO, Avezova R, Kossan G, Chew L, Maida CA. From systematic reviews to clinical recommendations for evidence-based health care: validation of revised assessment of multiple systematic reviews (R-AMSTAR) for grading of clinical relevance. Open Dent J. 2010;4:84-91.
6. Pussegoda K, Turner L, Garritty C, Mayhew A, Skidmore B, Stevens A, Boutron I, Sarkis-Onofre R, Bjerre LM, Hróbjartsson A, et al. Identifying approaches for assessing methodological and reporting quality of systematic reviews: a descriptive study. Systematic reviews. 2017;6(1):117.

7. Wegewitz U, Weikert B, Fishta A, Jacobs A, Pieper D. Resuming the discussion of AMSTAR: What can (should) be made better? BMC Med Res Methodol 2016; 16(1):111.

8. Moher D, Tetzlaff J, Tricco AC, Sampson M, Altman DG. Epidemiology and reporting characteristics of systematic reviews. PLoS Med. 2007;4(3):e78.

9. Page MJ, Shamseer L, Altman DG, Tetzlaff J, Sampson M, Tricco AC, CataláLópez F, Li L, Reid EK, Sarkis-Onofre R, et al. Epidemiology and reporting characteristics of systematic reviews of biomedical research: a crosssectional study. PLoS Med. 2016;13(5):e1002028.

10. Bouhassira D, Lanteri-Minet M, Attal N, Laurent B, Touboul C. Prevalence of chronic pain with neuropathic characteristics in the general population. Pain. 2008;136(3):380-7.

11. Torrance N, Smith BH, Bennett MI, Lee AJ. The epidemiology of chronic pain of predominantly neuropathic origin. Results from a general population survey. J Pain. 2006;7(4):281-9.

12. van Hecke O, Austin SK, Khan RA, Smith BH, Torrance N. Neuropathic pain in the general population: a systematic review of epidemiological studies. Pain. 2014;155(4):654-62.

13. Kamerman PR, Wadley AL, Davis KD, Hietaharju A, Jain P, Kopf A, Meyer AC, Raja SN, Rice AS, Smith BH, et al. World Health Organization essential medicines lists: where are the drugs to treat neuropathic pain? Pain. 2015;156(5):793-7.

14. Attal N, Bouhassira D. Pharmacotherapy of neuropathic pain: which drugs, which treatment algorithms? Pain. 2015;156(Suppl 1):S104-14.

15. Smith $\mathrm{BH}$, Torrance $\mathrm{N}$. Epidemiology of neuropathic pain and its impact on quality of life. Curr Pain Headache Rep. 2012;16(3):191-8.

16. IASP.: 2014-2015 Global Year Against Neuropathic Pain. 2015 https://www. iasp-pain.org/GlobalYear/NeuropathicPain 2017 June 22.

17. Attal N, Cruccu G, Baron R, Haanpaa M, Hansson P, Jensen TS, Nurmikko T. EFNS guidelines on the pharmacological treatment of neuropathic pain: 2010 revision. Eur J Neurol. 2010;17(9):1113-e1188.

18. Moulin D, Boulanger A, Clark AJ, Clarke H, Dao T, Finley GA, Furlan A, Gilron I, Gordon A, Morley-Forster PK, et al. Pharmacological management of chronic neuropathic pain: revised consensus statement from the Canadian Pain Society. Pain Res Manag. 2014;19(6):328-35.

19. NICE: Neuropathic pain-pharmacological management. 2013 https://www. nice.org.uk/guidance/cg1732017 July 22.

20. Finnerup NB, Attal N, Haroutounian S, McNicol E, Baron R, Dworkin RH, Gilron I, Haanpaa M, Hansson P, Jensen TS, et al. Pharmacotherapy for neuropathic pain in adults: a systematic review and meta-analysis. Lancet Neurol. 2015;14(2):162-73.

21. Cruccu G, Aziz TZ, Garcia-Larrea L, Hansson P, Jensen TS, Lefaucheur JP, Simpson BA, Taylor RS. EFNS guidelines on neurostimulation therapy for neuropathic pain. Eur J Neurol. 2007;14(9):952-70.

22. Dworkin RH, O'Connor AB, Kent J, Mackey SC, Raja SN, Stacey BR, Levy RM, Backonja M, Baron R, Harke $\mathrm{H}$, et al. Interventional management of neuropathic pain: NeuPSIG recommendations. Pain. 2013;154(11):2249-61.

23. IASP: IASP taxonomy. $2012 \mathrm{https://www.iasp-pain.org/}$ terminology?navltemNumber=576\#Neuropathicpain 2017 June 22.

24. AMSTAR working group: AMSTAR Checklist. www.amstar.ca 2017 June 22.

25. Gwet KL: Handbook of Inter-Rater Reliability, 4th Edition: The Definitive Guide to Measuring The Extent of Agreement Among Raters: Advanced Analytics, LLC; 2014

26. Thoma A, Veltri K, Haines T, Duku E. A meta-analysis of randomized controlled trials comparing endoscopic and open carpal tunnel decompression. Plast Reconstr Surg. 2004;114(5):1137-46.

27. Landis JR, Koch GG. The measurement of observer agreement for categorical data. Biometrics. 1977:33(1):159-74.

28. Advanced Analytics L: Inter-Rater Reliability With R. 2010 http://www. agreestat.com/r_functions.html 2017 June.

29. Martins DE, Astur N, Kanas M, Ferretti M, Lenza M, Wajchenberg M. Quality assessment of systematic reviews for surgical treatment of low back pain: an overview. Spine J. 2016; 16(5):667-675.

30. Song Y, Oh M, Park S, Park M, Kim K, Lee U: The Methodological Quality of Systematic Reviews and Meta-Analyses on the Effectiveness of Nonpharmacological Cancer Pain Management. Pain Manag Nurs 2015; 16(5):781-791. 
31. Pieper D, Buechter RB, Li L, Prediger B, Eikermann M. Systematic review found AMSTAR, but not R(evised)-AMSTAR, to have good measurement properties. J Clin Epidemiol 2015; 68(5):574-583.

32. Wongpakaran N, Wongpakaran T, Wedding D, Gwet KL. A comparison of Cohen's kappa and Gwet's AC1 when calculating inter-rater reliability coefficients: a study conducted with personality disorder samples. BMC Med Res Methodol. 2013;13(1):61.

33. Popovich I, Windsor B, Jordan V, Showell M, Shea B, Farquhar CM. Methodological quality of systematic reviews in subfertility: a comparison of two different approaches. PLoS One 2012; 7(12):e50403.

34. Moseley AM, Elkins MR, Herbert RD, Maher CG, Sherrington C. Cochrane reviews used more rigorous methods than non-Cochrane reviews: survey of systematic reviews in physiotherapy. J Clin Epidemiol. 2009;62(10):1021-30.

35. Fleming PS, Seehra J, Polychronopoulou A, Fedorowicz Z, Pandis N. Cochrane and non-Cochrane systematic reviews in leading orthodontic journals: a quality paradigm? Eur J Orthod. 2013;35(2):244-8.

36. Petticrew M, Wilson P, Wright $K$, Song F. Quality of Cochrane reviews is better than that of non-Cochrane reviews. BMJ. 2002;324(7336):545.

37. Han JL, Gandhi S, Bockoven CG, Narayan VM, Dahm P. The landscape of systematic reviews in urology (1998 to 2015): an assessment of methodological quality. BJU Int. 2017;119(4):638-49.

38. Dahm P: Raising the bar for systematic reviews with assessment of multiple systematic reviews (AMSTAR). BJU Int 2017, 119(2):193-193.

39. Hall AM, Lee S, Zurakowski D. Quality assessment of meta-analyses published in leading anesthesiology journals from 2005 to 2014. Anesth Analg. 2017;124(6):2063-7.

40. Genuneit J, Seibold AM, Apfelbacher CJ, Konstantinou GN, Koplin JJ, La Grutta S, Logan K, Flohr C, Perkin MR. The state of asthma epidemiology: an overview of systematic reviews and their quality. Clin Translat Allergy. 2017;7:12.

41. Park JY, Lee KH, Ku YJ, Cho SG, Kim YJ, Lee HY, Kim JH. Characteristics, Trends, and Quality of Systematic Review and Meta-Analysis in General Radiology between 2007 and 2015. Acad Radiol 2017; 24(8):1013-1022.

42. Riado Minguez D, Kowalski M, Vallve Odena M, Longin Pontzen D, Jelicic Kadic A, Jeric M, Dosenovic S, Jakus D, Vrdoljak M, Poklepovic Pericic T et a:: Methodological and Reporting Quality of Systematic Reviews Published in the Highest Ranking Journals in the Field of Pain. Anesth Analg 2017; 125(4):1348-1354.

43. Pieper D, Jacobs A, Weikert B, Fishta A, Wegewitz U. Inter-rater reliability of AMSTAR is dependent on the pair of reviewers. BMC Med Res Methodol. 2017;17(1):98.

44. Whiting P, Savović J, Higgins JPT, Caldwell DM, Reeves BC, Shea B, Davies P, Kleijnen J, Churchill R, group R. ROBIS: a new tool to assess risk of bias in systematic reviews was developed. J Clin Epidemiol. 2016;69:225-34.

45. Cochrane Colloquium: Development of AMSTAR 2. $2016 \mathrm{http}: / / 2016$ colloquium.cochrane.org/workshops/development-amstar-2 2017 July 02.

\section{Ready to submit your research? Choose BMC and benefit from:}

- fast, convenient online submission

- thorough peer review by experienced researchers in your field

- rapid publication on acceptance

- support for research data, including large and complex data types

- gold Open Access which fosters wider collaboration and increased citations - maximum visibility for your research: over $100 \mathrm{M}$ website views per year

At BMC, research is always in progress.

Learn more biomedcentral.com/submissions 